\title{
Tetralogy of Fallot in Spain: a nationwide registry-based mortality study across 36 years
}

\author{
Laura Llamosas-Falcón', Eva Bermejo-Sánchez², Germán Sánchez-Díaz 2,3,4, Ana Villaverde-Hueso ${ }^{2,3}$, \\ Manuel Posada de la Paz ${ }^{2,3}$ and Verónica Alonso-Ferreira ${ }^{2,3^{*}}$
}

\begin{abstract}
Background: Tetralogy of Fallot (TOF) is the most frequent cyanotic congenital heart defect. TOF mortality has fallen remarkably in recent years due to therapeutic advances. Accordingly, the aim of this study was to assess temporal and spatial variability in TOF-related mortality in Spain across the period 1981-2016, using data drawn from the nationwide population-based registry.

Methods: Annual deaths due to TOF were sourced from the Spanish National Institute of Statistics database by reference to International Classification of Diseases (ICD), 9th and 10th Revision codes, namely, ICD-9 code 745.2 (period 1981-1998) and ICD-10 code Q21.3 (period 1999-2016). Age-specific and age-adjusted mortality rates were calculated, as were standardised mortality ratios (SMRs) by province, district and municipality for the period 1999-2016.

Results: A total of 1035 deaths were attributed to TOF (57.78\% of them were men and $42.22 \%$ were women). The ageadjusted mortality rate ranged from 0.75 per 1,000,000 inhabitants (95\% confidence interval [CI]: 0-1.36) in 1981 to 0.03 per 1,000,000 (95\% Cl: 0.01-0.06) in 2016 for both sexes. In 2011, there was a change in the mortality trend, with a significant decrease of $49.22 \%$ per year $(p<0.001)$. In terms of geographical analysis, some areas with a significantly higher risk of TOF mortality were identified in the south of Spain, though no specific spatial pattern was in evidence.

Conclusion: The decrease in TOF mortality may be related to improvements in diagnostic and treatment techniques. More studies are needed to analyse regions with a higher mortality risk, in order to improve medical planning and resource allocation, and identify risk factors and preventive measures.
\end{abstract}

Keywords: Congenital heart defect, Tetralogy of Fallot, Mortality, Spain, Temporal-analysis, Spatial-analysis

\section{Background}

Tetralogy of Fallot (TOF) is a structural congenital heart defect characterised by the presence of four cardiac defects: infundibular stenosis of the pulmonary artery, overriding aortic root, ventricular septal defect, and right ventricle hypertrophy $[1,2]$. TOF has an estimated world-wide prevalence of 3 cases per 10,000 live births and can thus be considered a rare disease $[3,4]$. Despite its low prevalence, it ranks among the most frequent congenital heart defects (CHD). The global birth prevalence of CHD in the general

\footnotetext{
* Correspondence: valonso@isciii.es

${ }^{2}$ Institute of Rare Diseases Research (IIER), Instituto de Salud Carlos III, 28029 Madrid, Spain

${ }^{3}$ Centre for Biomedical Network Research on Rare Diseases (CIBERER), 28029

Madrid, Spain

Full list of author information is available at the end of the article
}

population is $0.8 \%$, and TOF represents $5-10 \%$ of all CHD $[5,6]$. A CHD study conducted at a regional level in Spain confirmed that TOF is the most frequent cyanotic CHD, with a birth prevalence of $0.41 \%$ [7]. At a European level, EUROCAT (the European population-based consortium registry on congenital anomalies) data show a significant increase in TOF prevalence from 2004 to 2012 [8]. In contrast, a recent nationwide registry-based study in Spain reported decreasing trends in mortality rates due to congenital anomalies from 1999 to 2013 [9].

In the absence of treatment, TOF's natural disease course leads to high morbidity and mortality [10]. Although mortality from this cause has been reduced as a consequence of the impact of surgical interventions, patients still have a high risk of premature death, as compared to the general

(C) The Author(s). 2019 Open Access This article is distributed under the terms of the Creative Commons Attribution 4.0 International License (http://creativecommons.org/licenses/by/4.0/), which permits unrestricted use, distribution, and 
population [11]. This serves to highlight the interest that lies in analysing and monitoring mortality directly related to TOF. Mortality analyses provide information on demographic change, and allow for socio-economic strategies to be designed with the aim of improving the health and well-being of the population [9, 12].

While several studies have specifically analysed TOF patient mortality following surgical repair of the defect [11, 13-15], others have focused on overall CHD mortality [16-18]. In addition, some other TOF studies report on long-term outcome and survival analyses [19-23].

As regards geographical variability, Garcia et al. [24] reported significant differences in the distribution of CHD cases with postnatal diagnosis in Colombia but failed to find any specific pattern in this distribution. In China, a progressive increase in the prevalence of atrial septal defect and patent ductus arteriosus was observed in areas of higher altitude [25]. A cluster of births with TOF was found in a largely agricultural area of North Carolina (USA) but there was insufficient evidence to conclude that this was due to any given environmental factor [26]. In Spain, a temporal and spatial analysis of CHD prevalence was carried out in the Valencian Region (Comunidad Valenciana) in the east of Spain, where the authors found a heterogeneous geographic pattern [27]. In a recent study mentioned above [9], a high risk of premature death due to congenital anomalies was specifically identified in the south of Spain but, apart from this analysis, no population-based studies on TOF-attributed mortality in Spain have been reported to date, and there is no nationwide study on the subject, all of which make the present study unique.

Accordingly, the aim of this study was to analyse the mortality trends due to TOF in Spain over a lengthy period of time spanning 36 years (1981-2016), in order to assess whether there has been some kind of trend, and to try and discern possible geographical differences in the risk of death attributed to this disease.

\section{Results}

A total of 1035 TOF-related deaths were identified in Spain during the period 1981-2016 (631 from 1981 to 1998, and 404 from 1999 to 2016), 57.78\% of which were males (598 males vs. 437 females). The mean age of death was $16.28 \pm 19.41$ years and the median was 5 years, with no statistically significant differences between the sexes $(p=0.100)$. In both sexes combined, the age groups "less than 1 year" and "1-4 years" registered the highest percentage of deaths (19 and 29.5\% respectively), meaning that $48.5 \%$ of the 1035 TOF deaths occurred before the age of 5 years.

Figure 1 depicts the age-specific mortality rates, with the mortality rate being highest among children under one year of age $(12.98$ per $1,000,000)$ and then dropping sharply after 5 years of age $(0.26$ per $1,000,000)$. The same pattern was observed for both males and females.

In terms of the trend over time, the crude TOF mortality rate was seen to drop from 1.11 per 1,000,000 in 1981 to 0.03 in 2016. The age-adjusted mortality rate, likewise for both sexes, decreased from 0.75 per 1,000,000 inhabitants (95\% confidence interval [CI]: $0-1.36$ ) in 1981 to 0.03 per 1,000,000 (95\% CI: 0.01-0.06) in 2016 (non-smoothed values). The Joinpoint model (Fig. 2a) showed that there was no significant trend in the adjusted rates from 1981 to 2010 but that from 2011 onwards there was a decrease of $49.22 \%$ per year $(p<0.001)$. The trend in age-adjusted rates is shown for each sex in Fig. 2b (smoothed values). In recent decades, a progressive decrease was in evidence,

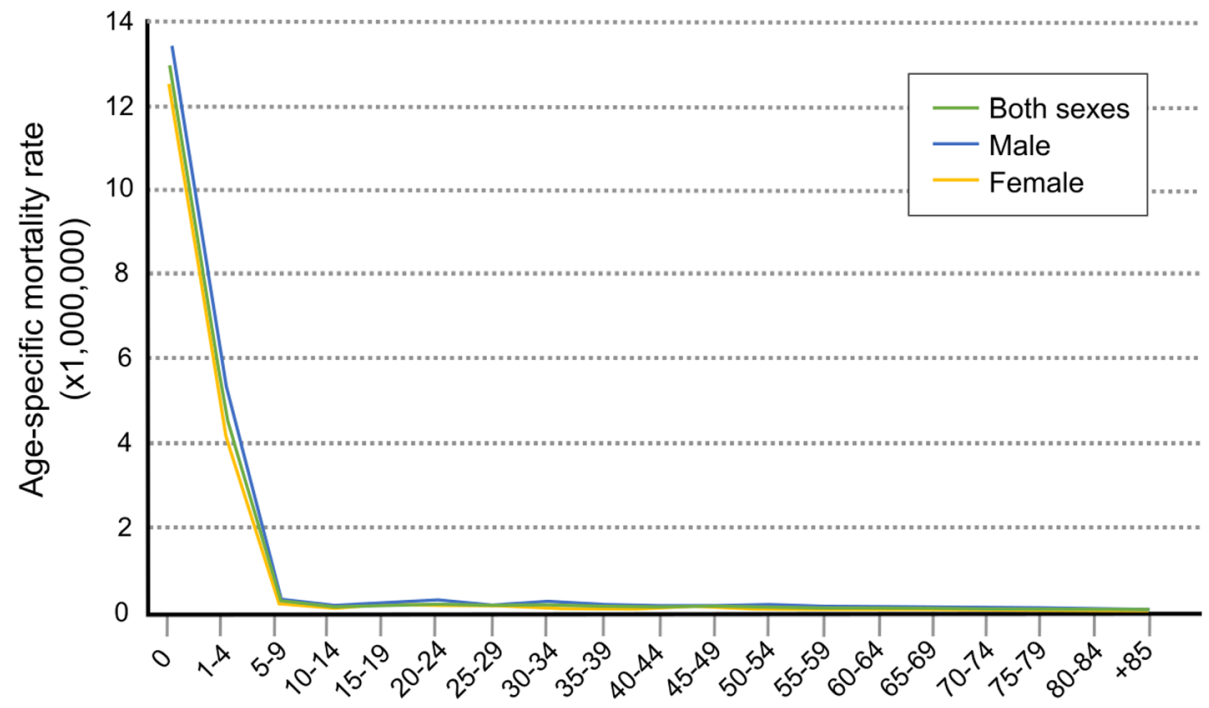

Fig. 1 Annual age-specific mortality rates attributed to Tetralogy of Fallot by sex 

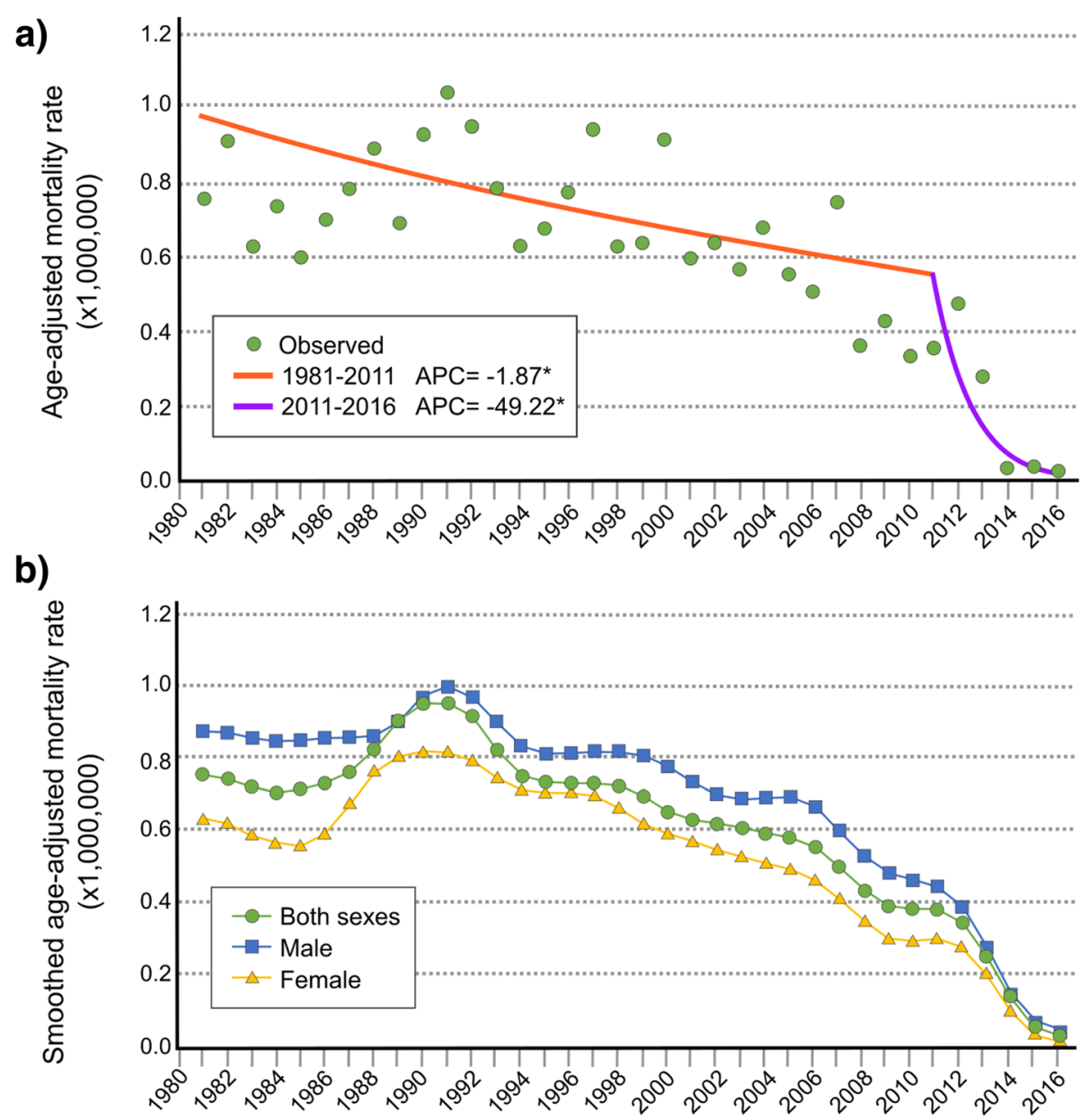

Fig. 2 Age-adjusted mortality rates due to Tetralogy of Fallot in Spain, 1981-2016. a Mortality trend plotted using a Joinpoint regression model; b Smoothed annual rates by sex

with the trend in smoothed rates being similar for both sexes, whether considered jointly or separately.

Insofar as the geographical analysis is concerned, the variability in SMRs across the period 1999-2016 is depicted in Fig. 3 with a breakdown by province, district and municipality. A heterogeneous distribution is observed without any evident defined spatial pattern. It would, however, seem that regions with SMRs higher than 1 are located mainly, though not exclusively, in areas of southern Spain. When the TOF mortality in adjacent regions (smoothed data not shown) was taken into account, the variability detected in the smoothed model was completely blurred, with no differences among municipal results.

Table 1 shows the provinces, districts and municipalities with SMRs significantly above or below 1 for the period 1999-2016. At a provincial level, whereas mortality in Madrid was significantly lower than expected (for both sexes combined and for males alone), it was significantly higher than expected (for both sexes) in Las Palmas. At a district level, the risk of mortality for both sexes combined was lower than expected in different districts of the province of Madrid ("Sur Occidental" and "Área Metropolitana"), and higher than expected in Las Palmas ("Gran Canaria"), Seville ("La Sierra Sur") and Murcia ("Suroeste"). Among females, the SMR was also higher than expected in one district of the province of Murcia ("Campo de Cartagena"), while among males the Madrid district of "Area Metropolitana" was identified as having a lower-than-expected SMR.

In the case of municipalities, as many as 27 had significantly higher risks of premature death, when both sexes were jointly analysed. Taking males and females separately, the number of municipalities with SMRs significantly higher than 1 was 22 and 13 respectively, and only one municipality had an SMR significantly lower than 1 , in men. These municipalities were distributed throughout the territory, without displaying any specific spatial grouping. 

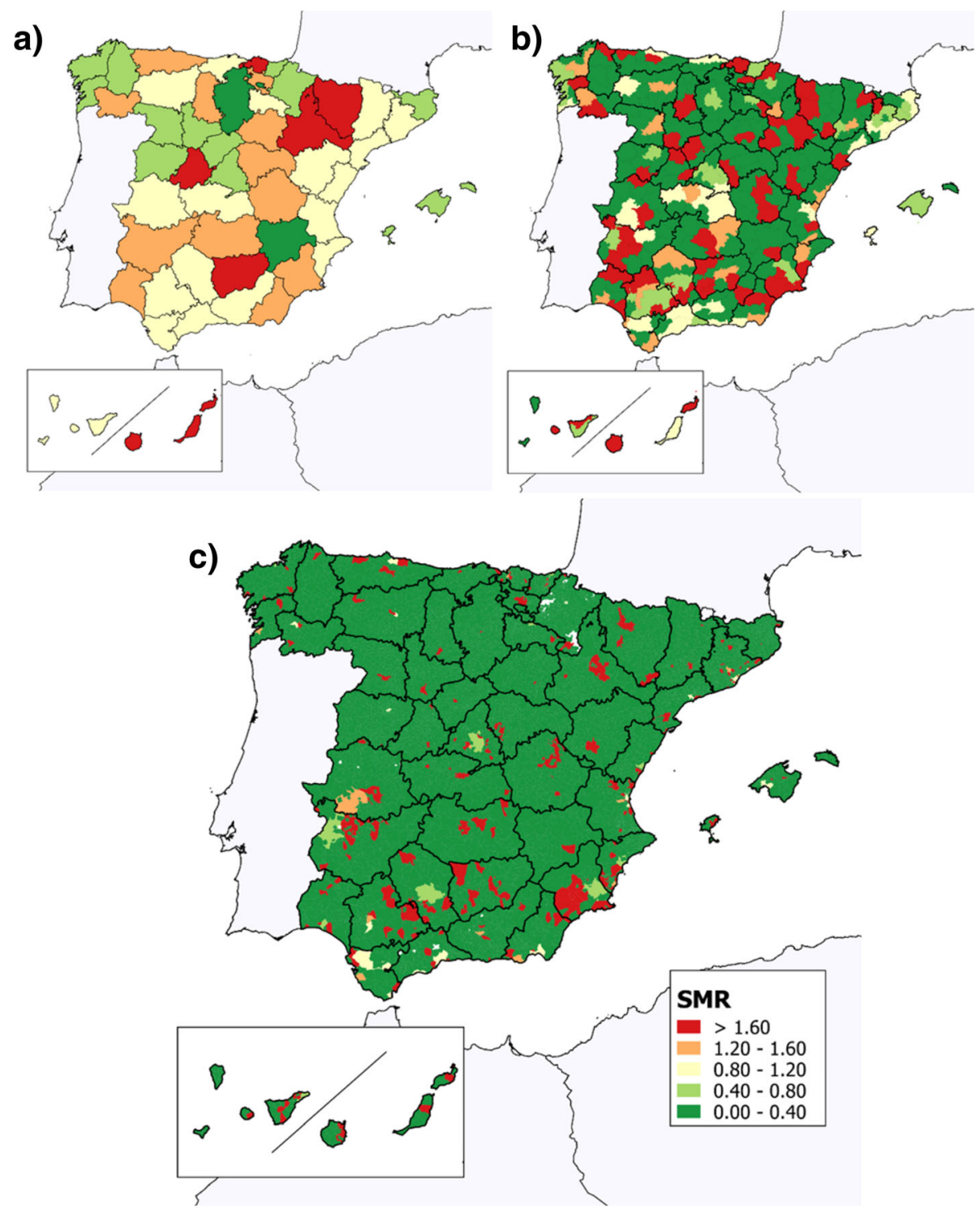

Fig. 3 Geographical representation of standardised mortality ratios (SMRs) for tetralogy of Fallot in Spain, 1999-2016. a Provinces; b Districts; c Municipalities

\section{Discussion}

This nationwide study, which is the first to analyse mortality directly related to TOF in Spain over a period of 36 years, detected a significant decrease in mortality rates since 2011 and a higher-than-expected risk of death in certain regions of the country.

This observed decline over time in mortality can be accounted for by several factors. Advances in prenatal diagnosis, that have enabled earlier detection of foetal anomalies [23, 28-31], specifically in Spain [32-34], plus advances in surgical intervention techniques [13, 14, 20,35], also in Spain [36], are the main factors identified as being responsible for the decrease in mortality. In addition, this downturn has also been influenced by the implementation of and improvement in cardiac rehabilitation programmes [37-39] coupled with ambulatory management and follow-up [40].

An increase in the prevalence of CHD in the period 2004-2012 was detected in EUROCAT, the populationbased registry of congenital anomalies, and attributed to the proliferation of the main risk factors associated with CHD [8]. Similarly, prevalence of CHD was observed to increase in the Valencian Region across the period 19992008, possibly due to improvements in diagnostic techniques [27]; and indeed, the spread in the use of such techniques might also account for part of this same rise. According to our data, the increase in prevalence observed by these studies has not triggered an increase in absolute TOF mortality figures in Spain, as might 
Table 1 Standardised mortality ratios (SMRs) by province, district and municipality in 1999-2016, and 95\% confidence intervals, global and by sex. Only those with statistically significant lower of higher-than-expected SMRs after indirect standardisation are shown

\begin{tabular}{|c|c|c|c|c|c|c|c|}
\hline Risk & Location & Province & District & Municipality ${ }^{\mathrm{b}}$ & Both sexes & Male & Female \\
\hline \multirow[t]{4}{*}{ Low risk } & $C$ & Madrid & & & $0.63(0.43-0.89)$ & $0.49(0.27-0.75)$ & \\
\hline & C & Madrid & Sur Occidental & & $0(0.00-0.59)$ & $0(0.00-0.99)$ & \\
\hline & C & Madrid & Area Metropolitana & & & $0.52(0.26-0.93)$ & \\
\hline & C & Madrid & Madrid & Horcajuelo de la Sierra & & $0.31(0.10-0.74)$ & \\
\hline \multirow[t]{15}{*}{ High risk } & $S W^{a}$ & Las Palmas & & & $1.80(1.05-2.89)$ & & \\
\hline & $S W^{\mathrm{a}}$ & Las Palmas & Gran Canaria & & $1.92(1.05-3.22)$ & & \\
\hline & SW & Seville & Sierra Sur & & $5.09(1.02-14.86)$ & & \\
\hline & SE & Murcia & Suroeste & & $2.88(1.05-6.27)$ & & \\
\hline & SE & Murcia & Campo de Cartagena & & & & $3.90(1.26-9.11)$ \\
\hline & $\mathrm{NE}$ & Barcelona & Osona & Gurb & $2.79(1.02-6.07)$ & & $4.65(1.25-11.90)$ \\
\hline & $\mathrm{N}$ & Vizcaya & Vizcaya & Arrankudiaga & $2.84(1.22-5.59)$ & $3.61(1.32-7.87)$ & \\
\hline & SE & Murcia & Suroeste & Aledo & $3.03(1.01-6.59)$ & & $5.10(1.37-13.05)$ \\
\hline & SW & Cadiz & La Janda & Barbate & $3.85(1.04-9.87)$ & & \\
\hline & C & Madrid & Campiña & Loeches & $9.44(1.06-34.07)$ & & $23.71(2.66-85.60)$ \\
\hline & E & Castellon & Llanos Centrales & Benasal & & $10.23(1.15-36.92)$ & \\
\hline & $\mathrm{N}$ & Palencia & Campos & Villovieco & & $10.41(1.17-37.58)$ & \\
\hline & $S W^{a}$ & Las Palmas & Fuerteventura & Oliva (La) & $11.06(1.30-41.88)$ & & \\
\hline & E & Valencia & Sagunto & Segart & & $13.97(1.57-50.44)$ & \\
\hline & $\mathrm{NE}$ & Barcelona & Osona & Tona & $14.98(1.68-54.08)$ & & \\
\hline
\end{tabular}

asland territories (Canary and Balearic Islands)

$\mathrm{C}=$ Centre; $\mathrm{E}=$ east; $\mathrm{N}=$ north; $\mathrm{NE}=$ north-east; $\mathrm{NW}=$ north-west; $\mathrm{S}=$ south; $\mathrm{SE}=$ south-east; $\mathrm{SW}=$ south-west; $\mathrm{W}=$ west

${ }^{\mathrm{b}}$ Small significant municipalities are not displayed because of the numerical instability (population $<5000$ inhabitants and SMR $>20$ )

have been expected. While elective terminations of pregnancy due to foetal anomalies (ETOPFA) are registered by EUROCAT, they do not appear in our analysis because NSI mortality figures do not include ETOPFA or stillbirths. In all probability, ETOPFA have contributed to the birth of a higher proportion of less severely affected cases, with a consequently lower risk of associated mortality $[41,42]$.

With regard to early diagnosis, in some cases this congenital anomaly can only be diagnosed postpartum. All intrauterine imaging methods have their limitations, despite the fact that there have been significant advances in these techniques [30]. Moreover, the prognosis for TOF cases detected in the prenatal period is worse than for those identified in the postnatal period, probably because the former tend to be more severely affected and this leads to their early detection. In fact, a higher incidence of chromosomal abnormalities, extra cardiac malformations and complex forms of TOF are usually associated with cases detected in the prenatal stage [29, 31]. Despite this, early diagnosis provides benefits when it comes to maintaining a close follow-up of the pregnancy [43]. This is also true for postnatally detected cases. The recent use of pulse oximetry for the screening of critical CHD is capable of detecting around six infants having a critical CHD such as TOF, among 10,000 apparently healthy newborn infants screened [44], and this will surely have an impact on morbidity and mortality in future analyses.

Age-specific mortality rates are higher in the first year of life and up to 5 years of age, decreasing thereafter with increasing age. It is important to take this information into account because it allows for those in charge of medical care to focus a special follow-up on this specific age range and monitor the different determinants of early death [9].

The number of patients reaching adult ages is in large part determined by the mortality arising from the surgery required in some cases, and by the increase of post-surgery survival over the years [13, 20, 22, 45-48]. This has given rise to an increasing number of surviving adults with complex CHD. Nevertheless, these patients still face premature death when they are young adults, with the causes of death mainly being heart failure or sudden death [17, 49]. The excess mortality in young adults as compared to the general population renders close specialist life-long follow-up of this group of patients advisable [17, 18, 50, 51].

In connection with age of death, studies suggest that, in an elderly population, the medical conditions of comorbidity acquired throughout life, including heart 
failure, diabetes, other chronic diseases and cancer, as well as advanced age per se, have a greater impact on mortality than suffering from a CHD $[16,52]$. This could also influence the lower risk observed by us of TOF-related death at older ages, for which there might well be a predominance of the above-mentioned causes.

In terms of geographical analysis, while some provinces show a lower-than-expected risk, a series of significantly higher-than-expected risks of TOF-related mortality were observed in some demarcations, mostly in southern Spain. Even so, the data analysed do not fit any definite spatial country-wide pattern. The study conducted by Nelson et al. in North Carolina (USA) showed a cluster of TOF cases in mainly agricultural areas but did not identify any specific environmental risk factors [26]. In their spatial analysis of CHD prevalence in the Valencian Region [27], the authors also found a heterogeneous geographical distribution which they felt might be due to differences in diagnostic accuracy and coding at hospitals. A recent nationwide registry-based study reported a higher risk of death attributed to congenital anomalies in the south of Spain [9]. Although the Spanish National Health System (SNHS) guarantees equal access to basic health services, variability between provinces might be related to different determinants, such as access to highly specialised facilities, longer or shorter follow-up of patients, or parents' attitudes to interruption of pregnancies in the case of foetuses affected with severe congenital heart defects. The data presented here did not allow for inference of any common local characteristics shared by the affected areas, but they constitute a body of evidence which should prompt new analytic studies and thereby allow possible links to be established between the disease's distribution patterns and possible underlying environmental risk factors. This would generate new evidence and could lead to prevention at different levels.

As for measures that could reduce CHD mortality, one would be the designation of referral centres specialised in the follow-up, care and treatment of these anomalies. Other authors have observed that neonatal mortality increases when fewer patients are treated at specialised centres [53]. In Sweden, centralisation of cases in institutions specialised in paediatric cardiac surgery reduced mortality in patients who underwent surgical interventions [54]. These specialised hospitals helped to adopt new treatment strategies in more complex cases and channel information about such strategies to local hospitals more easily. In addition, the policy served to stimulate interest in the field and direct research activities on paediatric diseases with surgical treatment. In Spain, a similar designation exists in the shape of SNHS Referral Centres, Services and Units (Centros, Servicios y Unidades de Referencia/CSUR). Our data might make it advisable to review patients' access to specific CSUR and their distribution across the country.

The limitations of this study include those usually attributed to death statistics, in which the underlying cause of death may be underestimated due to errors of diagnosis or coding, or to deaths being assigned to secondary complications instead of the disease itself, i.e., TOF. In addition, ETOPFA and stillborn cases were not included in our data (as vital statistics in Spain do not include these). Furthermore, the milder forms of TOF (with a lower mortality risk) can escape detection until older ages, potentially biasing the results towards more severe subtypes and higher overall mortality figures at younger ages.

Despite these limitations, the strength of this study lies in providing population-based information about officially reported deaths associated with this rare disease in Spain, over the span of 36 years. Its homogeneous, standardised and continuous methodology over time, allows this study contributing to monitoring mortality directly associated with TOF.

\section{Conclusions}

In conclusion, this is the first nationwide population-based study to analyse the time trend and spatial variability of TOF-related mortality in Spain. A decrease in mortality since 2011 was detected, as well as a heterogeneous distribution throughout the country. This study not only shows the utility of spatial modelling using population mortality data, but can also contribute to future studies focusing on environmental and even epigenetic risk factors. Lastly, it gives a global view of the country, which could be used for further analyses on access to specialised care and other health services, ranging from pre- and neonatal screening and surgery at early ages, to long-term care for adults or elderly living with CHD such as TOF. Our finding of a decrease in TOF-related mortality -and thus more persons surviving into adulthood- means that those reaching reproductive ages will need to be adequately informed about their risk of having affected offspring, information that can be provided by specialists in Genetics. Higher survival at adult ages also implies the need to understand the clinical course of this disorder, in order to provide optimal medical care and anticipate possible complications, with the aim of equalising life expectancy vis-à-vis that of the general population.

\section{Methods}

We designed and conducted an observational, retrospective, descriptive study. Annual deaths registered as due to TOF were sourced from the National Statistics Institute (NSI) of Spain. Deaths attributed to TOF as primary cause of death were identified by reference to International Classification of Diseases (ICD), 9th and 10th Revision 
codes for the underlying cause of death, namely, ICD-9 code 745.2 for the period 1981-1998 and ICD-10 code Q21.3 for the period from 1999 onwards.

In addition to collecting data on age, sex, year of birth, place of residence, registered year and place of death, we also obtained annual Spanish population data, broken down by sex, age and place of residence from the NSI, which we used to calculate annual sex- and age-group specific rates for each of the years studied.

We calculated the mean age at death, and compared the median age of death of men and women using the Mann-Whitney U test. Age-specific mortality rates and annual age-adjusted mortality rates were calculated by sex (direct standardisation using the standard European population as reference). The age-adjusted mortality rates were smoothed according to the non-parametric method T4253H [55] and the time trends were assessed using the Joinpoint regression model. All rates were expressed per 1,000,000 inhabitants.

The study area encompassed all of Spanish territory, made up of a total of 52 provinces, 326 districts and 8112 municipalities. For comparability reasons, geographical analysis considered the period 1999-2016 in which municipality identification was available in all TOF deaths. Standardised mortality ratios (SMRs) were calculated by province, district and municipality using the Spanish population as a reference (indirect method), with these data also being furnished by the NSI. The SMRs were subsequently smoothed taking into account information pertaining to adjacent geographical units, in accordance with the model proposed by Besag, York and Molliè [56]. No additional data transformation was made.

All statistical analyses were performed using the SPSS v15 (IBM Corporation, Chicago, IL, USA), EPIDAT v4.2 (General Directorate of Public Health, Galicia, Spain), Joinpoint v4.5.0.1 (National Cancer Institute, Bethesda, MD, USA) and R-INLA (Norwegian University of Science and Technology, Trondheim, Norway) computer software programmes, while QGIS v2.18.17 was used for cartographic representation purposes.

\section{Abbreviations \\ CHD: Congenital heart defects; Cl: Confidence interval; ETOPFA: Elective terminations of pregnancy due to foetal anomalies; ICD: International Classification of Diseases; NSI: National Statistics Institute; SMR: Standardised mortality ratio; SNHS: Spanish National Health System; TOF: Tetralogy of Fallot}

\section{Acknowledgements}

The authors would like to thank Michael Benedith for the valuable language support and English editing of the manuscript.

\section{Funding}

This research was funded by Instituto de Salud Carlos III, Spanish Strategy Action for Health (AESI), project TPY1238/15. The author G.S.D. received a research grant from the Spanish Ministry of Education, Culture and Sport, FPU14/03914.

\section{Availability of data and materials}

The datasets generated and/or analysed during the current study are available in the National Statistics Institute (NSI) repository, at https://www.ine.es/

\section{Authors' contributions}

Conceptualization, VA-F, EB-S and MPdIP; Methodology, VA-F, EB-S, LLL-F; Validation, GS-D and AV-H; Formal Analysis, LLL-F and GS-D; Investigation, LLL-F, EB-S and MPdIP; Resources, AV-H and VA-F; Data Curation, GS-D and AV-H; Writing - Original Draft Preparation, LLL-F, EB-S and VA-F; Writing-Review \& Editing, LLL-F, VA-F, AV-H, GS-D, MPdIP and EB-S; Visualization, GS-D; Supervision, VA-F and EB-S; Project Administration, VA-F; Funding Acquisition, VA-F. All authors read and approved the final manuscript.

\section{Ethics approval and consent to participate}

The study was conducted in accordance with the Declaration of Helsinki, and the protocol was approved by the Ethics Committee of the Instituto de Salud Carlos III (CEI 50/2013)

\section{Consent for publication}

Not applicable.

\section{Competing interests}

The authors declare that they have no competing interests.

\section{Publisher's Note}

Springer Nature remains neutral with regard to jurisdictional claims in published maps and institutional affiliations.

\section{Author details}

${ }^{1}$ Preventive Medicine and Public Health, Hospital Universitario 12 de Octubre, 28041 Madrid, Spain. ${ }^{2}$ Institute of Rare Diseases Research (IIER), Instituto de Salud Carlos III, 28029 Madrid, Spain. ${ }^{3}$ Centre for Biomedical Network Research on Rare Diseases (CIBERER), 28029 Madrid, Spain. ${ }^{4}$ Department of Geology, Geography and Environmental Sciences, University of Alcala, 28801 Alcalá de Henares, Spain.

Received: 31 January 2019 Accepted: 1 April 2019

Published online: 08 April 2019

\section{References}

1. Apitz C, Webb GD, Redington AN. Tetralogy of Fallot. Lancet. 2009;374:10.

2. Anderson RH, Weinberg PM. The clinical anatomy of tetralogy of Fallot. Cardiol Young. 2005:15(S1):38.

3. Bailliard F, Anderson RH. Tetralogy of Fallot. Orphanet J Rare Dis. 2009;4(1):2.

4. Alonso V, Villaverde-Hueso A, Hens M, Morales-Piga A, Abaitua I, Posada de la Paz M. Public health research on rare diseases. Georgian Med News. 2011; (193):11-6.

5. van der Linde D, Konings EEM, Slager MA, Witsenburg M, Helbing WA, Takkenberg JJM, et al. Birth prevalence of congenital heart disease worldwide. J Am Coll Cardiol. 2011;58(21):2241-7.

6. Pedersen LM, Pedersen TAL, Ravn HB, Hjortdal VE. Outcomes of pregnancy in women with tetralogy of Fallot. Cardiol Young. 2008;18(04).

7. Pérez-Lescure Picarzo J, Mosquera González M, Latasa Zamalloa P, Crespo Marcos D. Incidencia y evolución de las cardiopatías congénitas en España durante 10 años (2003-2012). An Pediatría. 2018;89(5):294-301.

8. Morris JK, Springett AL, Greenlees R, Loane M, Addor M-C, Arriola L, et al. Trends in congenital anomalies in Europe from 1980 to 2012. Palazón-Bru A, editor. PLoS One 2018:13(4):e0194986

9. Alonso-Ferreira V, Sánchez-Díaz G, Villaverde-Hueso A, Posada de la Paz M, Bermejo-Sánchez EA. Nationwide registry-based study on mortality due to rare congenital anomalies. Int J Environ Res Public Health. 2018;15(8):1715.

10. Bertranou EG, Blackstone EH, Hazelrig JB, Turner ME Jr, Kirklin JW. Life expectancy without surgery in tetralogy of Fallot. Am J Cardiol. 1978;42(3): $458-66$.

11. Niwa K, Hamada H, Nakazawa M, Terai M, Tateno S, Sugimoto S, et al. Mortality and risk factors for late deaths in tetralogy of Fallot: the Japanese Nationwide multicentric survey. Cardiol Young. 2002;12(5):453-60.

12. Mathers C, Boerma T. Mortality measurement matters: improving data collection and estimation methods for child and adult mortality. PLoS Med. 2010;7(4):e1000265. 
13. Knott-Craig CJ, Elkins RC, Lane MM, Holz J, McCue C, Ward KE. A 26-year experience with surgical management of tetralogy of fallot: risk analysis for mortality or late reintervention. Ann Thorac Surg. 1998;66(2):506-10.

14. Ismail SR, Kabbani MS, Najm HK, Abusuliman RM, Elbarbary M. Early outcome of tetralogy of Fallot repair in the current era of management. J Saudi Heart Assoc. 2010;22(2):55-9.

15. Cohen KE, Buelow MW, Dixon J, Brazauskas R, Cohen SB, Earing MG, et al. Forced vital capacity predicts morbidity and mortality in adults with repaired tetralogy of Fallot. Congenit Heart Dis. 2017;12(4):435-40.

16. Khairy P, lonescu-lttu R, Mackie AS, Abrahamowicz M, Pilote L, Marelli AJ. Changing mortality in congenital heart disease. J Am Coll Cardiol. 2010; 56(14):1149-57.

17. Greutmann M, Tobler D, Kovacs AH, Greutmann-Yantiri M, Haile SR, Held L, et al. Increasing mortality burden among adults with complex congenital heart disease. Congenit Heart Dis. 2015:10(2):117-27.

18. Engelfriet $P$, Boersma $E$, Oechslin E, Tijssen J, Gatzoulis MA, Thilén U, et al. The spectrum of adult congenital heart disease in Europe: morbidity and mortality in a 5 year follow-up period. Eur Heart J. 2005;26(21):2325-33.

19. Caruana M, Grech V. A first population-based long-term outcome study in adults with repaired tetralogy of Fallot in Malta. Congenit Heart Dis. 2017; 12(3):301-8.

20. Hickey EJ, Veldtman G, Bradley TJ, Gengsakul A, Manlhiot C, Williams WG, et al. Late risk of outcomes for adults with repaired tetralogy of Fallot from an inception cohort spanning four decades. Eur J Cardiothorac Surg. 2009; 35(1):156-64.

21. Chiu S-N, Wang J-K, Chen H-C, Lin M-T, Wu E-T, Chen C-A, et al. Long-term survival and unnatural deaths of patients with repaired tetralogy of Fallot in an Asian cohort. Circ Cardiovasc Qual Outcomes. 2012;5(1):120-5.

22. Nollert G, Fischlein T, Bouterwek S, Böhmer C, Klinner W, Reichart B. Longterm survival in patients with repair of tetralogy of Fallot: 36-year follow-up of 490 survivors of the first year after surgical repair. J Am Coll Cardiol. 1997; 30(5):1374-83.

23. Zhao Y, Abuhamad A, Fleenor J, Guo Y, Zhang W, Cao D, et al. Prenatal and postnatal survival of fetal tetralogy of Fallot: a meta-analysis of perinatal outcomes and associated genetic disorders. J Ultrasound Med. 2016;35(5): 905-15.

24. García A, Caicedo M, Moreno K, Sandoval N, Ronderos M, Dennis R. Diferencias regionales en cardiopatías congénitas. Rev Colomb Cardiol. 2017;24(2):161-8

25. Miao C-Y, Zuberbuhler JS, Zuberbuhler JR. Prevalence of congenital cardiac anomalies at high altitude. J Am Coll Cardiol. 1988;12(1):224-8.

26. Nelson JS, Stebbins RC, Strassle PD, Meyer RE. Geographic distribution of live births with tetralogy of Fallot in North Carolina 2003 to 2012: tetralogy of Fallot in NC. Birt Defects Res A Clin Mol Teratol. 2016;106(11):881-7.

27. Cavero Carbonell C, Zurriaga O, Pérez Panadés J, Barona Vilar C, Martos Jiménez C. Variación temporal y distribución geográfica de las cardiopatías congénitas en la Comunitat Valenciana. An Pediatría. 2013;79(3):149-56.

28. Prats P, Ferrer $Q$, Rodríguez M. Diagnóstico prenatal y evolución de cardiopatías congénitas. Diagn Prenat. 2011;22(4).

29. Poon LCY, Huggon IC, Zidere V, Allan LD. Tetralogy of Fallot in the fetus in the current era. Ultrasound Obstet Gynecol. 2007:29(6):625-7.

30. Nelle M, Raio L, Pavlovic M, Carrel T, Surbek D, Meyer-Wittkopf M. Prenatal diagnosis and treatment planning of congenital heart defects-possibilities and limits. World J Pediatr. 2009:5(1):18-22.

31. Allan LD, Sharland GK. Prognosis in fetal tetralogy of Fallot. Pediatr Cardiol. 1992;13:4.

32. Bajo Arenas JM, Pérez Medina T, Haya Palazuelos J. Sistemática de la exploración ecográfica durante la gestación. In: Tratado de ginecología y Obstetricia y Medicina de la reproducción. Madrid: Cabero L, Ed. Editorial Panamericana; 2003. p. 343-50. ISBN 3084-7903-754-7.

33. Sociedad Española de Ginecología y Obstetricia. Control prenatal del embarazo normal. Prog Obstet Ginecol. 2011;54(6):281-350

34. Sociedad Española de Ginecología y Obstetricia. Guía de la sistemática de la exploración ecográfica del primer trimestre. Guías prácticas de asistencia. Prog Obstet Ginecol. 2015. https://doi.org/10.1016/j.pog.2015.06.009.

35. Loomba RS, Buelow MW, Woods RK. Complete repair of tetralogy of Fallot in the neonatal versus non-neonatal period: a meta-analysis. Pediatr Cardiol. 2017:38(5):893-901.

36. Polo López L, Centella Hernández T, López Menéndez J, Silva Guisasola J. Cirugía de pacientes con cardiopatía congénita en España en el período
2012-2016: registro de intervenciones de la Sociedad Española de Cirugía Torácica-Cardiovascular. Cir Cardiov. 2017:24(6):368-80.

37. Dedieu N, Fernández L, Garrido-Lestache E, Sánchez I, Jesus Lamas M. Effects of a cardiac rehabilitation program in patients with congenital heart disease. Open J Intern Med. 2014;04(01):22-7.

38. Calzolari A, Turchetta A, Biondi G, Drago F, De Ranieri C, Gagliardi G, et al. Rehabilitation of children after total correction of tetralogy of Fallot. Int J Cardiol. 1990;28(2):151-8.

39. Márquez-Calderón S, Villegas Portero R, Briones Pérez de la Blanca E, Sarmiento González-Nieto V, Reina Sánchez M, Sáinz Hidalgo I, Velasco Rami JA, Ridocci Soriano F. [Incorporation of cardiac rehabilitation programs and their characteristics in the Spanish National Health Service]. Rev Esp Cardiol. 2003:56(8):775-82.

40. Kwon EN, Mussatto K, Simpson PM, Brosig C, Nugent M, Samyn MM Children and adolescents with repaired tetralogy of Fallot report quality of life similar to healthy peers. Congenit Heart Dis. 2011;6(1): $18-27$.

41. Carvalho JS. Clinical impact of first and early second trimester fetal echocardiography on high risk pregnancies. Heart. 2004:90(8):921-6.

42. Khoshnood B, De Vigan C, Vodovar V, Goujard J, Lhomme A, Bonnet D, et al. Trends in prenatal diagnosis, pregnancy termination, and perinatal mortality of newborns with congenital heart disease in France, 1983-2000: a population-based evaluation. Pediatrics. 2005;115(1):95-101

43. Lee W, Smith RS, Comstock CH, Kirk JS, Riggs T, Weinhouse E. Tetralogy of Fallot: prenatal diagnosis and postnatal survival. Obstet Gynecol. 1995;86(4 Pt 1):583-8.

44. Plana MN, Zamora J, Suresh G, Fernandez-Pineda L, Thangaratinam S, Ewer AK. Pulse oximetry screening for critical congenital heart defects. Cochrane Neonatal Group, editor Cochrane Database Syst Rev 2018.

45. Warnes CA. The adult with congenital heart disease. J Am Coll Cardiol. 2005 46(1):1-8

46. Naidu P, Grigg L, Zentner D. Mortality in adults with congenital heart disease. Int J Cardiol. 2017:245:125-30.

47. Alexiou C, Mahmoud H, Al-Khaddour A, Gnanapragasam J, Salmon AP, Keeton $B R$, et al. Outcome after repair of tetralogy of Fallot in the first year of life. Ann Thorac Surg. 2001;71(2):494-500.

48. Jonsson $H$, Ivert T. Survival and clinical results up to 26 years after repair of tetralogy of Fallot. Scand J Thorac Cardiovasc Surg. 1995;29(2):43-51.

49. Engelings CC, Helm PC, Abdul-Khaliq H, Asfour B, Bauer UMM, Baumgartner $\mathrm{H}$, et al. Cause of death in adults with congenital heart disease - An analysis of the German National Register for congenital heart defects. Int J Cardiol. 2016:211:31-6.

50. Verheugt CL, Uiterwal CSPM, van der Velde ET, Meijboom FJ, Pieper PG, van Dijk APJ, et al. Mortality in adult congenital heart disease. Eur Heart J. 2010;31(10):1220-9.

51. Greutmann M, Tobler D. Changing epidemiology and mortality in adult congenital heart disease: looking into the future. Futur Cardiol. 2012;8(2): $171-7$.

52. Afilalo J, Therrien J, Pilote L, Ionescu-Ittu R, Martucci G, Marelli AJ. Geriatric Congenital Heart Disease. 2011:58(14):7.

53. Lara DA, Fixler DE, Ethen MK, Canfield MA, Nembhard WN, Morris SA. Prenatal diagnosis, hospital characteristics, and mortality in transposition of the great arteries: prenatal diagnosis in TGA. Birt Defects Res A Clin Mol Teratol. 2016;106(9):739-48.

54. Lundström NR, Berggren H, Björkhem G, Jögi P, Sunnegårdh J. Centralization of pediatric heart surgery in Sweden. Pediatr Cardiol. 2000; 21(4):353-7.

55. Velleman PF. Definition and comparison of robust nonlinear data smoothing algorithms. J Am Stat Assoc. 1980:75(371):609-15.

56. Besag J, York J, Molliè A. Bayesian image restoration, with two applications in spatial statistics. Ann Inst Stat Math. 1991:43(1):1-20. 